\title{
CARACTERIZAÇÃO DA PROTEÇÃO MARCARIA DO AGRONEGÓCIO \\ BRASILEIRO: uma visao com base em dados do inpi
}

\begin{abstract}
Resumo: O presente trabalho buscou analisar com base em dados do INPI a situação dos pedidos de registros de Marcas relacionadas ao setor do Agronegócio. A Marca de um produto ou serviço tem como objetivo levar o nome da empresa ao mercado e como tal ela se traduz em ativos valiosos para as organizações contribuindo para seu reconhecimento social e crescimento econômico. A pesquisa consistiu em verificar os seguintes aspectos: segmentos que mais registraram as Marcas, tipo de apresentação da marca, natureza da marca, titularidade, situação dos registros e evolução anual dos registros. Os resultados demonstram que para o período analisado (1998 até junho de 2017) foram encontrados 549 pedidos registros de marcas para o segmento pesquisado, desses registros, $89,80 \%$ foram efetuados por pessoa jurídica, quanto aos setores se destacam o de Comércio de insumos agrícolas com $40,25 \%$ dos pedidos, o de Publicidade e comunicação no geral com 12,39\%. Já com relação à natureza das marcas, a Marcas de Serviços representam 76,87\% dos processos e quanto à forma de apresentação a Mista concentra 79,42\% dos pedidos.
\end{abstract}

Palavras-chave: Marcas. Registro. Agronegócio. Proteção.
Maria José Castro Professora do EBTT IFS, doutoranda em Ciência da Propriedade Intelectual Universidade Federal de Sergipe, Brasil, mariajdecastro2@gmail.com

Sidney Rodrigues Tapajós UNIP/ICEC/MT, Brasil. tapajos.sidney@gmail.com

Petrojanes Stellato Filho UNIVAG/MT, Brasil. stellato@stellato.eng.br

Joao Antonio Belmino dos Santos do Professor do Programa de Pós-Graduação em Ciência da Propriedade Intelectual UFSM, Brasil, joaoantonio@ufs.br

\section{CHARACTERIZATION OF BRAZILIAN AGRIBUSINESS MARKING PROTECTION: a view based on inpi data}

\begin{abstract}
The present work sought to analyze, based on data from INPI, the status of requests for trademark registrations related to the Agribusiness sector. The Brand of a product or service aims to take the name of the company to the market and as such it translates into valuable assets for organizations contributing to their social recognition and economic growth. The research consisted of the following aspects: segments that registered the most Marks, type of presentation of the brand, nature of the brand, ownership, status of the records and annual evolution of the records. The results show that, for the analyzed period (1998 to June 2017), 549 trademark applications were found for the researched segment, of which $89,80 \%$ were made by legal entity, as regards the sectors of Trade in inputs With $40.25 \%$ of the requests, Advertising and general communication with $12.39 \%$. Regarding the nature of the brands, the Service Marks represent $76.87 \%$ of the processes and as regards the presentation to Mista, it concentrates $79.42 \%$ of the requests.
\end{abstract}

Keywords: Trademarks. Registration. Agribusiness. Protection. 


\section{INTRODUÇÃO}

O setor do Agronegócio no Brasil vem cada vez mais se estruturando e apresenta uma expressiva participação na economia do país. Este segmento econômico tem contribuído com aproximadamente $23 \%$ do PIB nos últimos anos, segundo dados da Confederação da Agricultura e Pecuária do Brasil $(\underline{\mathrm{CNA}})^{1}$, além de contribuir para colocar o país com líder mundial na produção e exportação de alguns produtos, onde o Brasil tem se destacado como o terceiro maior produtor e exportador agrícola do mundo e o setor que mais contribui para o saldo positivo da balança comercial brasileira.

Segundo dados do Ministério da Indústria, Comércio Exterior e Serviços (MICS) ${ }^{2}$, no primeiro semestre de 2016, dos 10 principais produtos brasileiros exportados no período, que trouxeram ao Brasil US\$ 41,6 bilhões em receita, com destaque para soja em grão, açúcar bruto, celulose e carne bovina.

Em termos conceituais, o agronegócio é compreendido pelo conjunto de atividades e empresas que produzem insumos agrícolas, as propriedades rurais, as empresas de processamento e toda a distribuição, envolvendo assim, as operações de produção e distribuição de suprimentos agrícolas; das operações de produção na fazenda; do armazenamento, processamento e distribuição dos produtos agrícolas e itens produzidos a partir deles. (DAVIS E GOLDBE, 1957; CALLADO, 2006).

No entendimento que o setor do Agronegócio é constituído de todos os processos e atividades que estão relacionados com a agricultura e também com a pecuária, e é responsável pela integração de diversos setores da economia brasileira, possibilitando a confecção de roupas, a elaboração de produtos de higiene pessoal, gerando cerca de 189 milhões de empregos diretos e indiretos. (CNA, 2017).

Visando entender a contribuição desse segmento no contexto do registro de marcas perante o Instituto Nacional de Propriedade Industrial (INPI) o presente trabalho buscou identificar o comportamento e características do registro de Marcas do setor do Agronegócio, para tanto foi verificado os seguintes aspectos: segmentos que mais registraram as Marcas,

\footnotetext{
${ }^{1}$ O PIB do agronegócio mede a geração de riquezas em todas as cadeias do setor agropecuário, desde a produção de insumos até as indústrias de alimentos, passando pela produção nas fazendas. http://www.cnabrasil.org.br/ . Acesso em 20 de junho de 2017.

${ }^{2}$ Ministério da Indústria, Comércio Exterior e Serviços (MICS). http://www.mdic.gov.br/index.php/balancacomercial. Acesso em 20 de junho de 2017.
} 
tipo de apresentação da marca, natureza da marca, titularidade, situação dos registros e evolução anual dos registros. Esta pesquisa se caracteriza como do tipo exploratório com abordagem qualitativa (interpretação dos dados). A coleta de dados foi realizada no Banco de dados do Instituto Nacional de Propriedade Industrial (INPI) do Brasil na parte de Marcas, em 20 de junho de 2017 onde foi utilizado como palavra-chave o termo “Agronegócio”.

\section{FUNDAMENTOS TEÓRICOS}

\subsection{MARCA: ASPECTOS CONCEITUAIS E LEGAIS}

A Marca de um produto ou serviço tem como objetivo levar o nome da empresa ao mercado e como tal ela se traduz em ativos valiosos para as organizações contribuindo para seu reconhecimento social e crescimento econômico. Nesse sentido, Fazzio Júnior, 2008, destaca que as marcas são "sinais visualmente perceptíveis (símbolos, figuras, nomes, emblemas etc.) utilizados para fins distintivos, tendo como finalidade individualizar os produtos ou serviços de uma empresa".

Conforme destacado por Coelho, 2010, a Marca é:

"o designativo que identifica produtos e serviços", sendo que "a proteção da marca
se restringe aos produtos e serviços com os quais o marcado pode ser confundido
pelo consumidor. Se não houver a possibilidade de confusão - isto é, de o
consumidor considerar que o fornecedor de certo produto ou serviço é o mesmo de
outro com marca igual ou semelhante - não decorrerá do registro nenhum direito
de exclusividade". (COELHO, 2010).

Conforme a Organização Mundial da Propriedade Intelectual (OMPI, 2003) a marca é um sinal capaz de distinguir os produtos ou serviços de uma empresa daqueles de outras empresas, sendo consideradas marcas quaisquer palavras ou letras distintas, números, desenhos, imagens, formas, cores, logomarcas, rótulos ou combinações usadas para identificar os produtos ou serviços de uma empresa. Em alguns países também se reconhecem como marcas as campanhas publicitárias, que podem ser registradas como tal nos escritórios nacionais de marcas.

A função principal da marca é facilitar ao consumidor a identificação de um produto (bem ou serviço) de uma empresa específica, para que ele possa diferenciá-lo de outros produtos idênticos ou semelhantes da concorrência. Também tem a função de satisfazer as necessidades psicológicas das pessoas, o que lhe confere a característica de intangibilidade, 
acarretando assim, tantas outras como diferenciação, a criação de laços afetivos e a satisfação das necessidades utilitárias dos consumidores. (OMPI, 2003; TOLEDO, 2013).

Na visão de Porto, 2011, a função principal e jurídica de uma marca é a de distinguir bens e serviços de outros da mesma espécie, mantendo ainda uma unicidade distintiva suficiente para ocupar um inconfundível lugar no mercado, destacando ainda algumas funções, a saber:

- Distintiva: considerada essencial juridicamente, é a partir da distinção que o proprietário da marca tem o seu direito de usufruto garantido.

- Indicação de origem: tem como função indicar a origem empresarial do produto e/ou serviço;

- Publicitária: responsável por criar uma imagem da marca, fazendo a sua promoção e divulgação, intensificando assim a fama de determinada marca;

- Qualidade: com enfoque econômico disponibilizado por seu titular com o intuito de ampliar a sua vantagem competitiva (PORTO, 2011).

As marcas podem ser classificadas, em função de sua natureza e de sua apresentação. Quanto à sua natureza ou objeto a ser identificado, o art. 123 da LPI estabelece quatro espécies de marca, a saber, Quadro 1.

Quadro 1: Natureza da marca

\begin{tabular}{|l|l|}
\hline $\begin{array}{l}\text { NATUREZA DA } \\
\text { MARCA }\end{array}$ & \multicolumn{1}{c|}{ CARACTERÍSTICA } \\
\hline Marca de produto & $\begin{array}{l}\text { É aquela utilizada para distinguir produto de outro idêntico, semelhante ou afim, } \\
\text { de origem diversa. }\end{array}$ \\
\hline Marca de Serviço & $\begin{array}{l}\text { É aquela utilizada para distinguir serviço de outro similar, idêntico ou afim, de } \\
\text { origem diversa. }\end{array}$ \\
\hline Marca de Certificação & $\begin{array}{l}\text { É aquela utilizada para atestar a conformidade de um produto ou serviço com } \\
\text { determinadas normas ou especificações técnicas, especialmente quanto à } \\
\text { qualidade, natureza, material utilizado e metodologia empregada; e }\end{array}$ \\
\hline Marca Coletiva & $\begin{array}{l}\text { É aquela utilizada para identificar produtos ou serviços derivados de membros } \\
\text { de um determinado grupo ou entidade. }\end{array}$ \\
\hline $\begin{array}{l}\text { Marcas notoriamente } \\
\text { conhecidas }\end{array}$ & $\begin{array}{l}\text { Marcas que são consideradas muito conhecidas no mercado e por isso gozam de } \\
\text { uma proteção mais forte }\end{array}$ \\
\hline
\end{tabular}

Fonte: adaptado Instituto Nacional de Propriedade Industrial - Disponível em: www.inpi.gov.br

Uma marca de serviço é muito parecida com uma marca de produto, mas ambos são sinais distintivos; as marcas de produto distinguem os produtos de uma empresa dos produtos das outras empresas, enquanto as marcas de serviço exercem a mesma função com relação aos serviços. Pode se tratar de qualquer tipo de serviço, tais como financeiros, bancários, turísticos, publicitários ou de restauração, para dar alguns exemplos, e podem ser registradas, renovadas, canceladas, cedidas e licenciadas, sob as mesmas condições que as marcas de produto. (OMPI, 2003). 
Já as marcas coletivas geralmente pertencem a uma associação ou cooperativa cujos membros possam utilizar esta marca coletiva para comercializar os seus produtos. Normalmente a associação estabelece uma série de critérios para o uso da marca coletiva (por exemplo, padrões de qualidade) e autoriza cada empresa associada a utilizar a marca desde que respeite tais critérios, podendo ser utilizadas como um meio eficaz para a comercialização conjunta dos produtos de um grupo de empresas para as quais seria mais difícil levar os consumidores a reconhecer as suas próprias marcas e/ou levarem os principais distribuidores a aceitar a distribuição dos seus produtos. (OMPI, 2003).

Quanto ao aspecto da sua apresentação, as marcas são classificadas da seguinte maneira: Quadro 2. Formas de apresentação da Marca

\begin{tabular}{|l|l|}
\hline $\begin{array}{l}\text { FORMAS DE } \\
\text { APRESENTAÇÃO }\end{array}$ & \multicolumn{1}{c|}{ FORMA DE CONFIGURAÇÃo } \\
\hline Marca Nominativa & $\begin{array}{l}\text { É aquela composta por palavras, neologismos e combinações de letras e/ou número } \\
\text { do nosso alfabeto e sinais gráficos e de pontuação. }\end{array}$ \\
\hline Marca Figurativa: & $\begin{array}{l}\text { Constituída por desenho, imagem, ideograma, forma fantasiosa ou figurativa de } \\
\text { letra ou algarismo, e palavras compostas por letras de alfabetos como hebraico, } \\
\text { ciŕlico, árabe, etc. }\end{array}$ \\
\hline Marca Mista & $\begin{array}{l}\text { É aquela composta pela combinação de imagens e palavras (elementos nominativos } \\
\text { e figurativos). }\end{array}$ \\
\hline $\begin{array}{l}\text { Marca } \\
\text { Tridimensional }\end{array}$ & $\begin{array}{l}\text { Pode ser considerada marca tridimensional a forma de um produto, quando é capaz } \\
\text { de distingui-lo de outros produtos semelhantes. }\end{array}$ \\
\hline
\end{tabular}

Fonte: adaptado Instituto Nacional de Propriedade Industrial - Disponível em: www.inpi.gov.br

Ainda existe o registro especial de marca considerada de ALTO RENOME (anteriormente denominada NOTÓRIA): ALTO RENOME: É a marca que, processada de uma forma diversa dos processos normais, quando concedida garante o direito de uso exclusivo em todos os ramos de atividade, assegurando proteção especial. As marcas podem ser ainda classificadas quanto à sua origem, ao objeto a ser identificado (uso) e à proteção. Quanto à origem podem ser marcas brasileiras e marcas estrangeiras. A primeira, para todos os efeitos, é aquela regularmente depositada no Brasil, por pessoa domiciliada no País. Já a marca estrangeira, segundo o INPI:

é aquela regularmente depositada no Brasil, por pessoa não domiciliada no País, ou aquela que, depositada regularmente em país vinculado a acordo ou tratado do qual o Brasil seja partícipe, ou em organização internacional da qual o País faça parte, é também depositada no território nacional no prazo estipulado no respectivo acordo ou tratado, e cujo depósito no País contenha reivindicação de prioridade em relação à data do primeiro pedido. (INPI, 2017) 
Na Lei de Propriedade Industrial (Lei 9.279/96) ainda constam as marcas comuns, de alto renome e notoriamente conhecidas. As marcas de alto renome são aquelas conhecidas no Brasil, em toda a sua extensão territorial, e, nos termos do art. 125 da LPI, têm proteção especial em todos os ramos de atividade. No entanto, é indispensável o registro no Brasil. E as marcas notoriamente conhecidas são aquelas assim consideradas em seu ramo de atividade e estão previstas na Convenção da União de Paris, no art. $6^{\circ}$-bis, inciso 1 , bem como estão reguladas pelo art. 126 da LPI, o qual faz remissão ao dispositivo da Convenção.( BRASIL,1996, BARROS, 2012, INPI,2013).

\subsection{ASPECTOS GERAIS DO REGISTRO DA MARCA}

A Marca é considerada uma propriedade industrial e como tal para ter sua proteção garantida deve ter seu registro junto ao Instituto Nacional de Propriedade Industrial (INPI) fato esse assegurado pela legislação pátria, que garante a propriedade ou titularidade de uma marca. $\mathrm{O}$ registro de uma marca dá à empresa o direito exclusivo de impedir que terceiros comercializem produtos idênticos ou semelhantes com uma marca igual ou tão semelhante que possa causar confusão entre os consumidores, garantido direitos de licenciamento tornando-se uma fonte suplementar de renda para o seu negócio, ou pode ainda ser a base de um contrato de franquia. (BARBOSA, 2003, OMPI, 2003).

Quanto aos aspectos legais do registro da marca conforme exaltado por Barbosa (2003) “Os nomes mágicos” fazem parte do segmento de proteção legal da propriedade intelectual, fazendo parte da mais importante das propriedades intelectuais, haja vista ser considerada pelas empresas americanas a de maior relevância. (BARBOSA, 2003).

A proteção industrial concedida por registro ${ }^{3}$ de Marca ou proteção das marcas é garantida no Brasil pela Constituição Federal (1988) e regulamentado pela Lei de Propriedade Industrial (LPI- Lei n ${ }^{\circ}$ 9.279/96 LPI Artigos 122 a 175), e o responsável pela sua concessão é o Instituto Nacional de Propriedade Industrial (INPI). De acordo com a Lei $n^{\circ}$ 9.279/1996, em seu artigo 122, no tocante ao registro de marcas "São suscetíveis de registro como marca os sinais distintivos visualmente perceptíveis, não compreendidos nas proibições legais", Verificando-se sempre a distintividade e a anterioridade, ou seja, o título só será concedido se for de fato inovativo.

\footnotetext{
${ }^{3}$ Para saber mais sobre registro consultar: INPI http://manualdemarcas.inpi.gov.br/projects/manual/wiki/05 Exame_substantivo
} 
No caso do registro, quando da concessão da marca pelo INPI, a legislação assegura ao seu titular o uso exclusivo em todo o território nacional. O titular pode autorizar terceiros a utilizar sua marca ou impedir outras pessoas de utilizá-la para distinguir produtos ou serviços, idênticos, semelhantes ou afins. Como requisitos cumulativos de registrabilidade estão a novidade relativa, a distintividade e a licitude. No primeiro requisito, novidade, exige-se que a marca seja nova no mercado, no sentido de que não deve existir outra, idêntica ou semelhante, anteriormente adotada por terceiro (artigo 124, XIX, da LPI). . (BRASIL, 1996, INPI, 2013).

Ainda quanto ao registro da marca junto ao INPI, o usuário deve indicar em seu pedido quais produtos ou serviços que aquela marca visa a proteger. O INPI adota a Classificação Internacional de Produtos e Serviços de Nice (NCL, na sigla em inglês), que possui uma lista de 45 classes com informações sobre os diversos tipos de produtos e serviços e o que pertence a cada classe. É importante ressaltar que o registro concedido pelo INPI garante ao seu proprietário o direito de uso exclusivo no território nacional em seu ramo de atividade econômica. As marcas registradas e, por isso, legalmente protegidas, são identificadas com o símbolo ®. (INPI, 2013).

Depois de concedido, o registro de marca vigora por 10 (dez) anos, porém caso o titular do registro tenha interesse, pode pedir a prorrogação do registro por mais dez anos, sendo que a marca registrada garante ao seu proprietário o direito de uso exclusivo no território nacional em seu ramo de atividade econômica. É importante ressaltar que o registro concedido pelo INPI tem validade apenas no Brasil. E apesar de não ser compulsório, o registro é altamente recomendável, uma vez que ele confere direitos exclusivos ao titular para prevenir o uso não autorizado da marca. (BRASIL, 1996; OMPI, 2003; INPI, 2013).

\section{METODOLOGIA}

Esta pesquisa se caracteriza como do tipo exploratório com abordagem qualitativa (interpretação dos dados) e objetivou verificar junto ao INPI o comportamento e características do registro de Marcas do setor do Agronegócio junto ao INPI, para tanto foi verificado os seguintes aspectos: segmentos que mais registraram as Marcas, tipo de apresentação da marca, natureza da marca, titularidade, situação dos registros e evolução anual dos registros. A coleta de dados foi realizada no Banco de dados do Instituto Nacional 
de Propriedade Industrial (INPI) do Brasil na parte de Marcas, em 20 de junho de 2017 onde foi utilizado como palavra-chave o termo "Agronegócio".

\subsection{CARACTERÍSTICAS DAS BUSCAS NO INPI}

A coleta de dados junto ao INPI resultou em 549 processos entre os anos de 1998 até 20 de junho de 2017. No que diz respeito aos pedidos de proteção para marcas do "Agronegócio", a pesquisa evidenciou que o primeiro registro de marca relacionado ao termo ocorreu em 1998. No link de busca do INPI é possível efetuar dois tipos de pesquisa: a básica e a avançada. Optou-se pela avançada que permite filtrar algumas características como: tipo de apresentação e natureza da Marca. Sendo assim, foi efetuada a análise de 549 processos encontrados conforme os parâmetros delimitados para a pesquisa. Um dos parâmetros pesquisados foi a análise da situação das marcas considerando-se os tipos de despachos realizados pelo INPI, conforme Quadro 3, vale salientar que dentre os procedimentos e despachos efetuados pelo INPI pode haver outros tipos de despachos, destaca-se nessa pesquisa os que tiveram mais ocorrências.

\begin{tabular}{|l|l|}
\hline \multicolumn{2}{|l}{ Quadro 3. Tipos de despachos } \\
\hline Tipo de despacho & Significado \\
\hline Sobrestamento mérito & $\begin{array}{l}\text { É a análise em si do pedido de registro de marca, o momento no qual é verificado } \\
\text { se o sinal em trâmite está de acordo com o previsto na Lei da Propriedade } \\
\text { Industrial. }\end{array}$ \\
\hline Deferimento & $\begin{array}{l}\text { É o despacho de natureza preliminar pelo qual, antes do pronunciamento quanto } \\
\text { ao mérito do pedido de registro, ou seja, ele se encontra momentaneamente } \\
\text { paralisado, por existirem anterioridades pendentes de decisão. }\end{array}$ \\
\hline Indeferimento & $\begin{array}{l}\text { Ocorre quando o sinal examinado não infringe nenhum dispositivo legal e atende } \\
\text { às condições de registrabilidade previstas. }\end{array}$ \\
\hline Oposição & $\begin{array}{l}\text { O indeferimento é o despacho de natureza terminativa pelo qual é denegado o } \\
\text { pedido de registro de marca pela infringência de proibição prevista em lei. }\end{array}$ \\
\hline $\begin{array}{l}\text { Recurso } \\
\text { extraordinário }\end{array}$ & $\begin{array}{l}\text { Uma petição por meio da qual um terceiro se manifesta contra pedido de registro } \\
\text { infringência de proibições previstas em lei. }\end{array}$ \\
\hline $\begin{array}{l}\text { Ocorre quando o processo é julgado procedente, mas o requerente não recolhe as } \\
\text { taxas no decurso normal do prazo (60 dias), a partir de então se passa a contar o } \\
\text { prazo extraordinário com multa de 50\% e aso não pague o processo é arquivado } \\
\text { (perdido). }\end{array}$ \\
\hline
\end{tabular}

Fonte: http://manualdemarcas.inpi.gov.br/projects/manual/wiki/05_Exame_substantivo

\section{RESULTADOS E DISCUSSÕES}

Buscou-se verificar os segmentos que mais registraram as Marcas, tipo de apresentação da marca, natureza da marca, titularidade, situação dos registros (situação dos 
despachos dos processos) e evolução anual dos pedidos de registros de marca. Conforme as informações pesquisadas, buscou-se conhecer os segmentos que mais efetuou pedidos de proteção de marcas junto ao INPI, (Gráfico 1), sendo que do total (549) de processos encontrados foi possível identificar facilmente 8 segmentos. Dentre os segmentos identificados, o que mais apresentou pedido de registro de marcas está concentrado no setor de Comércio de insumos agrícolas com 221 processos, cerca de 40,25\% do total dos pedidos.

Ainda com relação aos segmentos (Gráfico 1), cabe destaque para o setor Publicidade e comunicação no geral com 68 processos, ou seja, 12,39\% dos pedidos. E nesse segmento cabe destaque para os pedidos de proteção de marcas das editoras e canais de televisão. Também tem certa relevância os pedidos de registros para os segmentos Associação de produtores e Federações com 37 processos o que corresponde a 6,73\% do total de pedidos.

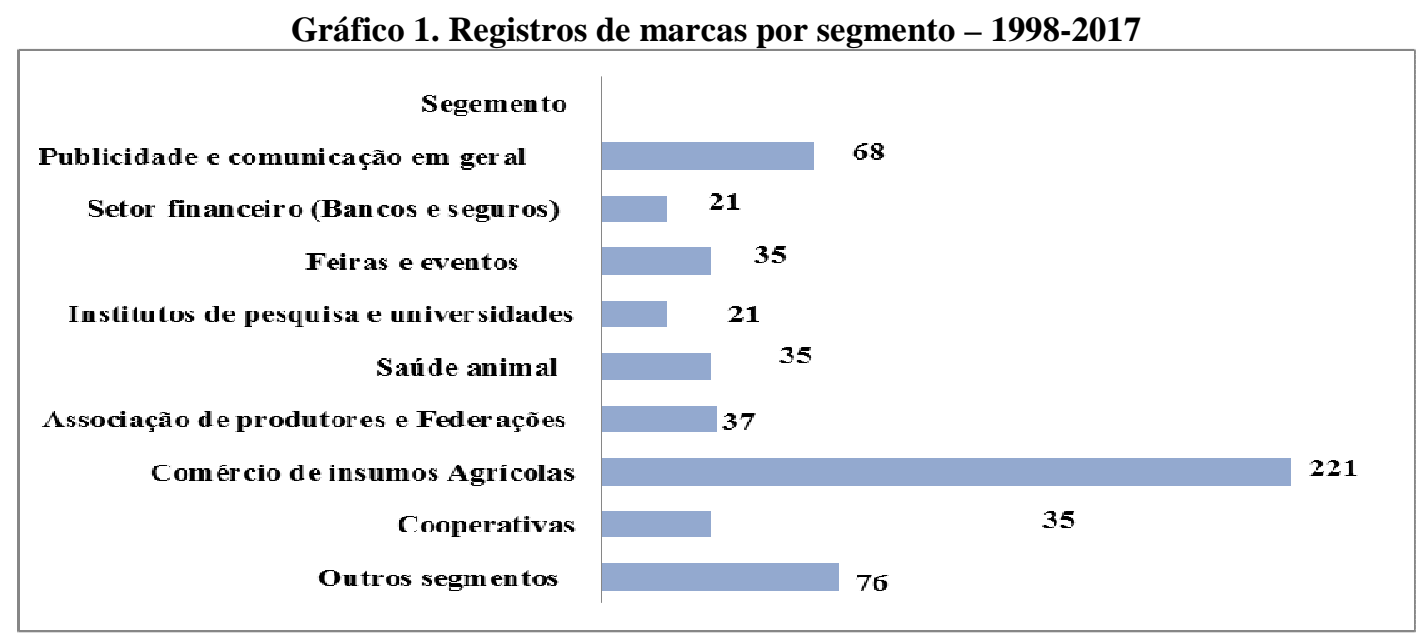

Fonte: autores- dados da pesquisa

Já os segmentos de Cooperativas e Saúde Animal (Gráfico 1), apresentaram 35 processos cada um. Segundo dados do INPI (Boletim jun/2017), os pedidos de proteção de marcas do setor de Cooperativas representam $0,3 \%$ dos pedidos do período de janeiro a junho de 2017, esse número evidencia a pouca importância que o setor atribui à proteção de marcas, pois o setor de cooperativas possui cerca de 6.800 cooperativas no país, distribuído em todos os Estados, com maior concentração nas regiões sul e sudeste do país, com uma participação anual de 7,3\% no PIB mineiro, o setor, que agrega 1373.173 associados e 36.128 empregados, é responsável por uma movimentação anual de $\mathrm{R} \$ 38,3$ bilhões ${ }^{4}$.

\footnotetext{
${ }^{4}$ http://www.minasgerais.coop.br/pagina/33/numeros.aspx.
} 
Quanto à verificação da situação em que se encontram os pedidos de registros de marcas (Gráfico 2), destaca-se que 187 pedidos de registos de marca, ou seja, 34,06\% tiveram êxito no registro sendo concedido ao solicitante o direito de uso da marca e que ainda encontram-se com seu direito de uso em vigor ( marcas em vigência).

Ainda com relação ao gráfico 2, outra situação que merece destaque está a relacionado ao Exame de mérito que consiste na análise em si do pedido de registro de marca, onde é verificado se o sinal em trâmite está de acordo com o previsto na Lei da Propriedade Industrial. Segundo INPI (2013) esta situação ocorre após a fase de publicação e eventuais oposições de terceiros, inicia-se a fase de exame de mérito pelos examinadores do INPI, que verificarão se os requisitos de registrabilidade de uma marca foram devidamente atendidos. Nessa situação a pesquisa apontou 140 pedidos, ou seja, 25,50\% dos processos e vale destacar que nesse esse tipo de condição se encontram os últimos processos protocolados de 2015 em diante.

Gráfico 2- Situação dos pedidos junto ao INPI

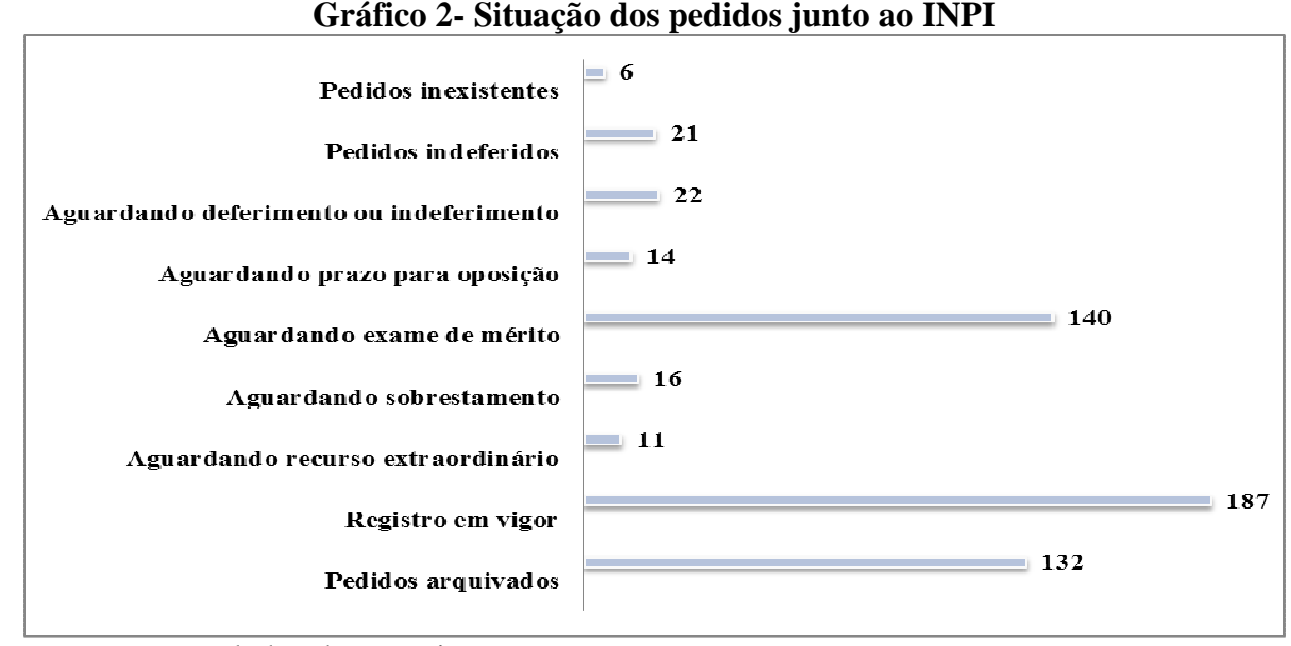

Fonte: autores- dados da pesquisa

Também merece destaque no gráfico 2, o número de processos arquivados 132 pedidos, ou seja, do total de 549, processos encontrados, cerca de $24,04 \%$ dos pedidos foram arquivados, o que é um índice relativamente alto, dentre os motivos de arquivamento estão a falta de pagamento das taxas, o não atendimento as diretrizes de registro de marcas etc.

Outro ponto pesquisado foi aas formas de apresentação das Marcas, como demonstrado no quadro 2, as marcas podem ser apresentadas de 04 formas, nominativa, figurativa, mista e tridimensional, com relação a esse aspecto os dados pesquisados no período de 1998 a junho de 2017 apresentaram (gráfico 3). 
Gráfico 3- Formas de apresentação da Marca

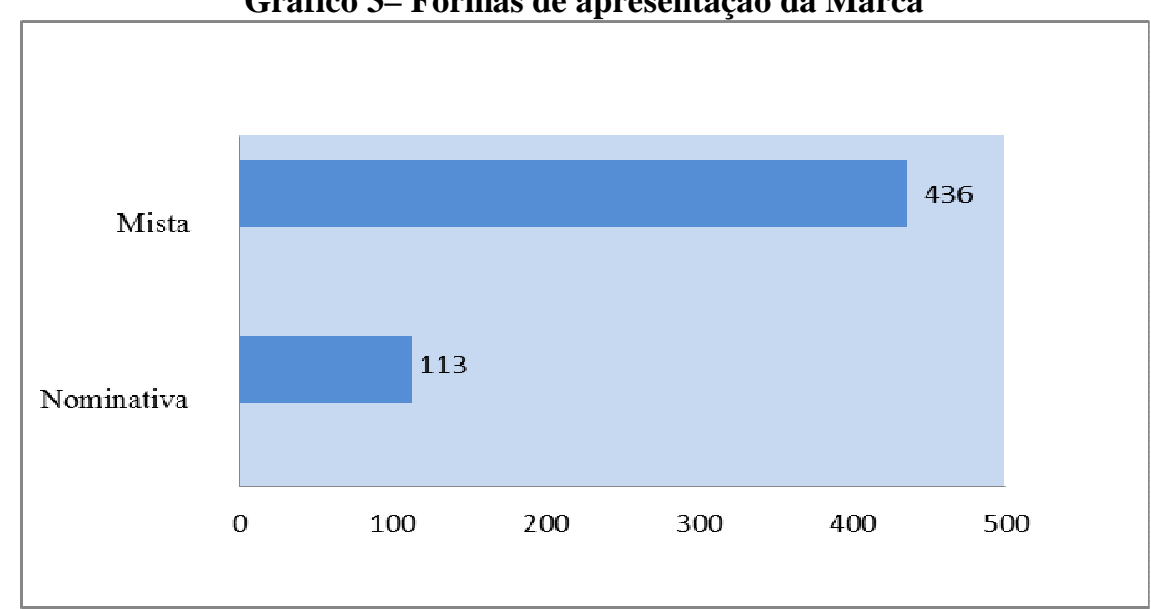

Fonte: autores- dados da pesquisa

A pesquisa evidenciou que as formas de apresentação (Gráfico 3), do total processos encontrado (549), desse total, 436 processos, o correspondente da 79,42\% figuram como do tipo Marca Mista (uma marca composta por uma mistura de elementos nominativos e figurativos), como exemplo a marca demonstrada no Figura 1 das marcas das empresas Vegetal Agronegócios e Granel Agronegócios..

Figura 1. Exemplo da forma de apresentação Mista
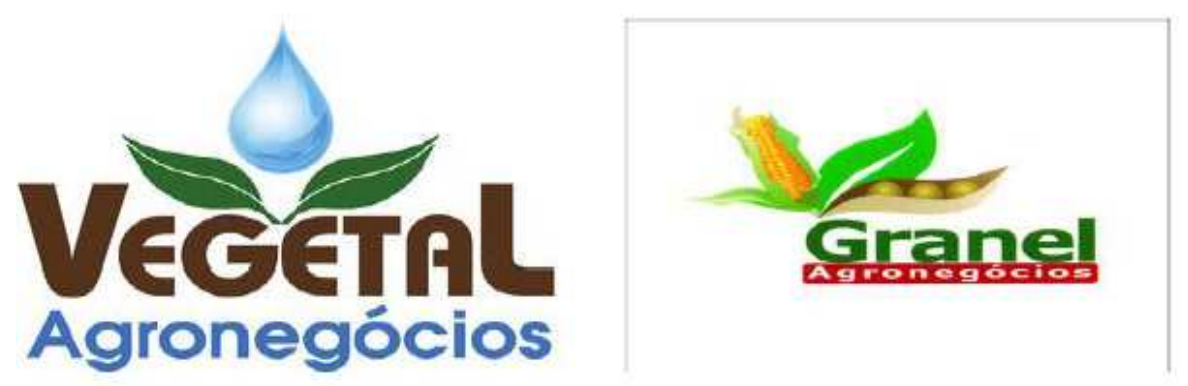

Fonte: adaptado com o nome das marcas protegidas no INPI

Para a forma de apresentação Nominativa foi encontrado 113 pedidos, ou seja, 20,58\% do total de processos encontrados na pesquisa. Esse tipo de marca se caracteriza por ser composta exclusivamente por letras, número, sinais gráficos e de pontuação.

A pesquisa também buscou conhecer a natureza de proteção das marcas (Gráfico 4), que diz respeito ao tipo produto ou serviço ao qual a marca se vincula, como destacado no Quadro 1 anteriormente. E nesse aspecto, o artigo 123 da LPI classifica as três formas de 
registro de marca: marca de produto ou serviço, marca de certificação e marca coletiva. A marca de produto ou serviço distingue um produto ou serviço de outro idêntico, semelhante ou afim, de origem diversa. A marca de certificação é usada para atestar a conformidade de um produto ou serviço com determinadas normas ou especificações técnicas, notadamente quanto à qualidade, natureza, material utilizado e metodologia empregada. E a marca coletiva identifica produtos ou serviços provindos de membros de uma determinada entidade (BRASIL, 1996, INPI, 2013).

\section{Gráfico 4 - Natureza de proteção das Marcas}

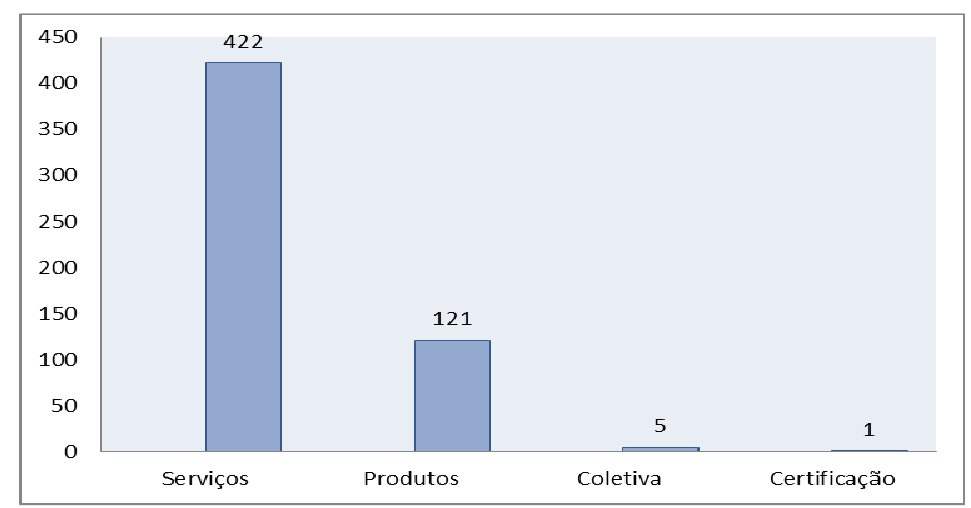

Fonte: autores- dados da pesquisa

Com relação à natureza das marcas, do total de processos (549) encontrados, 422 pedidos corresponde a Marcas de Serviços, o que corresponde a 76,87\% dos dados localizados na modalidade de busca avançada na página do INPI. No tipo de marca de produtos houve 121 registros, aproximadamente $22,04 \%$ do total. Também foi encontrado 5 marcas de natureza coletiva e 1 de Certificação.

Na pesquisa também se buscou conhecer a tipologia da titularidade das marcas, se pessoa física ou jurídica, Gráfico 5.

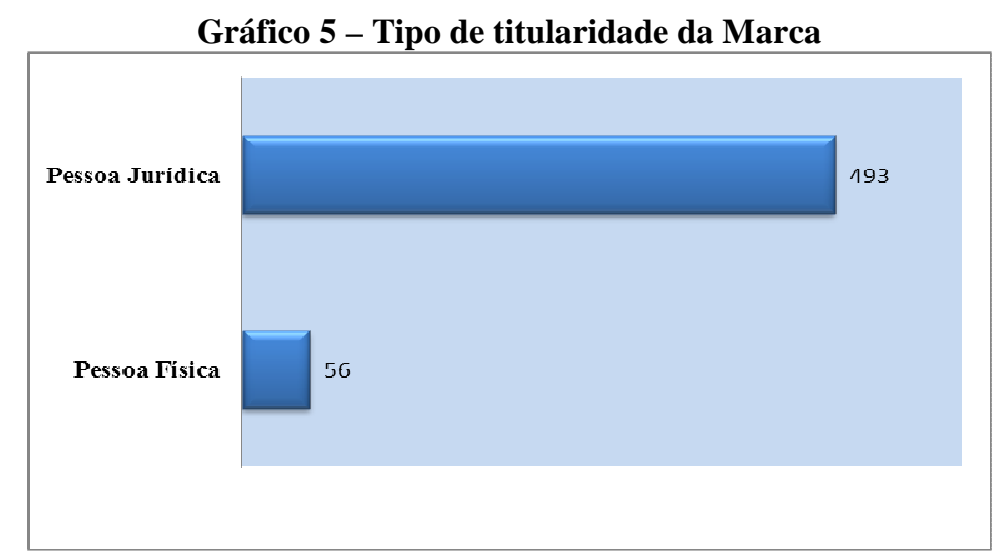

Fonte: autores- dados da pesquisa 
A pesquisa demonstrou que, do total de 549 pedidos de registros de marcas encontrados no período de 1998 a junho de 2017, um total de 493 pedidos, ou seja, 89,80\% dos registros foram efetuados por pessoa jurídica e 56 registros foram efetuados por pessoa física. Segundo Boletim do INPI ${ }^{5}$, para o período de janeiro a junho de $2017,75 \%$ dos pedidos de marcas foi efetuado por pessoa jurídica (50\% por empresas pequeno porte e $25 \%$ por empresas de médio e grande porte) e $22 \%$ por pessoa física.

A pesquisa também buscou analisar como se comportou os registros de marcas do setor do agronegócio, entre os anos de 1998 ate junho de 2017, como demonstra o gráfico 6 .

Gráfico 6 - Evolução anual dos pedidos de registros de marca

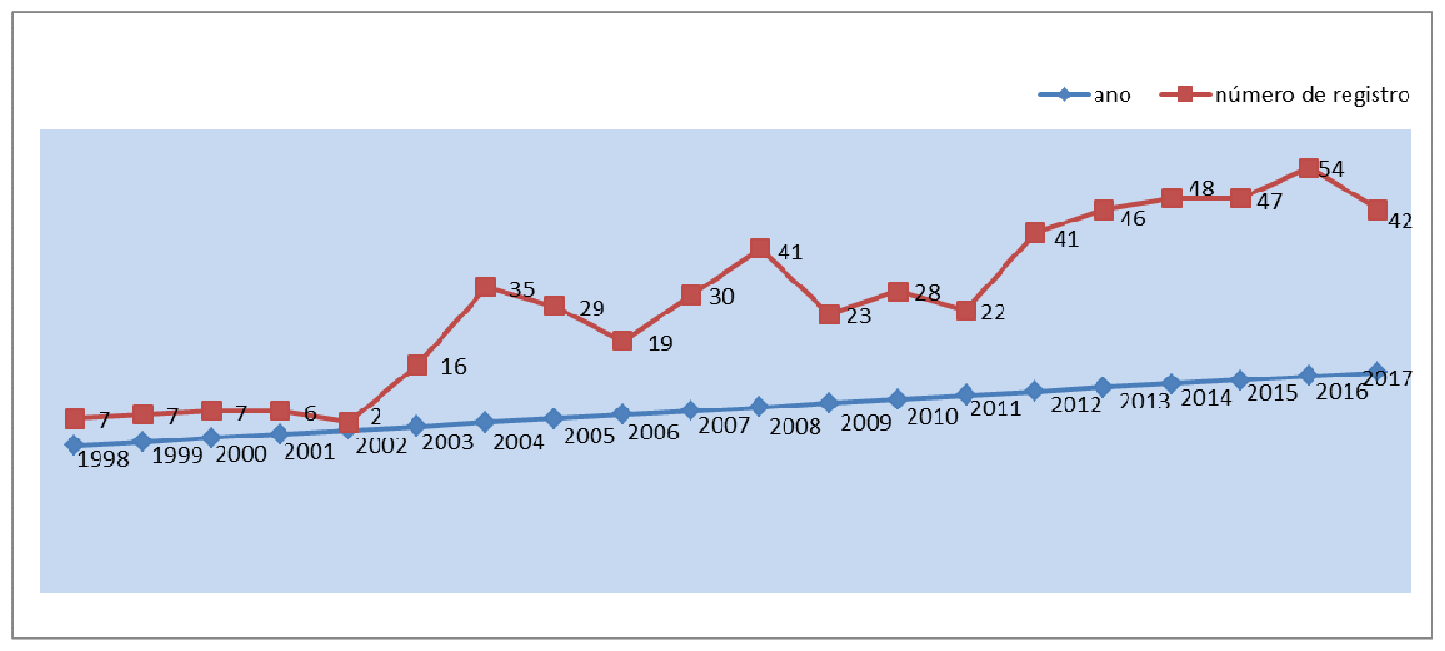

Fonte: autores- dados da pesquisa

$\mathrm{Na}$ evolução dos pedidos de registros de marca para o segmento pesquisado no período de 1998 ate junho de 2017 se observa como demonstra o gráfico 6 que esses registros se comportaram de forma mais tímida até os anos de 1998 ate'2003, mas que a partir de 2004 ( 35 pedidos) houve um crescimento de mais de $50 \%$ dos pedidos se comparado ao ano de 2003 com 16 registros. Já para os anos seguintes se destaca o ano de 2008 com 41 registros, e para o período de 2012 até a data da pesquisa manteve-se entre 41 e 54 pedidos por ano.

Devido aos parâmetros estabelecidos na pesquisa não se pode afirmar que esse número de pedidos é baixo, até porque as opções de buscas e termos agregados podem gerar quantitativos diferentes, portanto não reflete a importância do segmento, o que evidencia

\footnotetext{
${ }^{5}$ INPI,(2017) Boletim http://www.inpi.gov.br/sobre/estatisticas/arquivos/publicacoes/boletim_jun-2017.pdf. Acesso em 20 de junho de 2017.
} 
também a pouca importância que os empresários e demais instituições atribuem ao registro de uma marca.

\section{CONSIDERAÇÕES FINAIS}

O setor do Agronegócio brasileiro vem nos últimos anos recebendo a atenção por parte do governo, tanto federal quanto nos estados, mediante aporte de investimentos, políticas de incentivo à produção agrícola, a produção de commodities e o desenvolvimento de complexos agroindustriais, contribuindo para impulsionar o setor, tanto que no período de 2007 a 2017 (últimos 10 anos) houve um grande crescimento do agronegócio brasileiro, colocando o Brasil como um líder mundial na produção e exportação de produtos agrícolas e pecuários.

Vale destacar que devido às características da pesquisa, adoção do temo "agronegócio" para busca de registro de marcas o quantitativo encontrado com certeza não reflete a importância do segmento pesquisado, haja vista que o INPI recebe anualmente uma média anual de 160.000 pedidos de registros de marcas (todos os tipos de empresas) e o acumulado até maio para o ano de 2016, está em 69.296 pedidos e 41.788 concessões de marcas ${ }^{6}$.

Infere-se então, que é se de suma importância que as organizações agreguem valor à marca de seus produtos e serviços e que busquem a proteção legal mediante o registro junto ao INPI visando protegê-la em território nacional. Mas, muitos empresários brasileiros ainda desconhecem esse direito, não se interessam em proceder à proteção de suas as marcas, não visualizando oportunidades de retorno de seus investimentos.

Como destacado por Toledo, 2013, a relevância do registro de uma marca "deve-se ao fato de que a mesma consistirá no pilar de acesso aos clientes, do mesmo modo que irá atuar na vulnerabilidade de ação da concorrência, pois a proteção garante ao proprietário da marca o valor da sua organização junto ao consumidor".

\footnotetext{
${ }^{6}$ INPI, 2017. Estadísticas do INPI.http://www.inpi.gov.br/noticias/inpi-registra-aumento-de-produtividade-emmaio/view. Acessado em 20 de junho de 2017.
} 


\section{REFERÊNCIAS}

BARBOSA, D. B.(2003). Uma Introdução à Propriedade Intelectual. 2a . Edição. Rio de Janeiro: Ed. Lumen Juris.

BARROS, V.A. (2012).Conflito entre Marca e Nome Empresarial. RDE No 24 - JanFev/2012 - PARTE GERAL - DOUTRINA. Disponível em: http://bdjur.tjdft.jus.br/xmlui/bitstream/handle/123456789/12752/Conflito\%20entre\%20marca $\% 20 \mathrm{e} \% 20$ nome $\% 20 \mathrm{empresarial} . p d f ?$ sequence $=1$

BRASIL.(1996). Lei n. 9.279, de 14 de maio de 1996. Regula direitos e obrigações relativos à propriedade industrial. Diário Oficial da União. Brasília, DF, 15 maio 1996. Seção 1, p. 8353.

CAlladO, A. A. (2006). Cunha. Agronegócio. 1. ed. São Paulo: Atlas..

CNA.(2017).CONFEDERAÇÃO DA AGRICULTURA E PECUÁRIA DO BRASIL - CNA. Disponível em: < http://www.cna.org.br/site/agencia/>. Acesso em: 20 junho 2017

COELHO, F.U.(2010). Curso de Direito Comercial. 14. Ed. São Paulo: Saraiva, 2010. v. 2.

DAVIS, J. H; GOLDBERG, R. A.(1957). A concept of agribusiness. Boston: Harvard University. 1957. $135 \mathrm{p}$.

FAZZIO JÚNIOR, W. (2008). Manual de direito comercial. 9. Ed. São Paulo: atlas, 2008.

INPI. (2013). Instituto Nacional da Propriedade Industrial (Brasil). A criação de uma marca: uma introdução às marcas de produtos e serviços para as pequenas e médias empresas/ Instituto Nacional da Propriedade Industrial. - Rio de Janeiro: INPI, 2013 http://www.inpi.gov.br/sobre/arquivos/01_cartilhamarcas_21_01_2014_0.pdf. Acessado em $\underline{10.06 .2017}$

GONÇALVES, M.F.W. (2007). Propriedade industrial e a proteção dos nomes geográficos: indicações geográficas, indicações de procedência e denominações de origem. Curitiba: Juruá. OMPI, 2003. A criação de uma marca. Série sobre A Propriedade Intelectual para o Comércio e a Indústria. http://www.wipo.int/edocs/pubdocs/pt/sme/900/wipo_pub_900.pdf . Acessado em: 20 de junho de 2017.

PORTO, P. C. da R.(2011). Quando a Propriedade Intelectual Representa Qualidade: Marcas Coletivas, Marcas de Certificação e Denominação de Origem. $1^{a}$ edição. Rio de Janeiro. Lumen Juris Editora.

TOLEDO, A. C. (2013). Efeito da Nostalgia do Cliente na Lealdade à Marca Pós Fusão/Aquisição. Dissertação de Mestrado. Programa de Pós-Graduação em Administração da Universidade Nove de Julho - UNINOVE. São Paulo. 